\title{
Factors affecting follow-up non-attendance in patients with Type 2 diabetes mellitus and hypertension: a systematic review
}

Rayson Rui Sheng $\underline{\operatorname{Lee}}^{1}$, BBM, Mas'uud Ibnu Samsudin${ }^{1}$, BSc(Hons), Thiru Thirumoorthy ${ }^{1}$, MBBS, FRCP, Lian Leng Low ${ }^{2}$, MBBS, MMed, Yu Heng $\underline{K w a n}^{1}$, BSc(Hons)

This is a systematic review of the factors and reasons associated with follow-up non-attendance (FUNA) in patients with Type 2 diabetes mellitus and hypertension in an outpatient setting. We performed a systematic literature search using electronic databases and related keywords with the PRISMA-P checklist, focusing on the factors, types of studies and number of studies that showed a positive, negative or neutral association with FUNA. Data was presented in three categories: patient, disease and medication, and healthcare provider factors. In total, 4,822 articles were reviewed. Among the 24 articles that were relevant to the stated objective, 83 factors were found to be associated with FUNA. A target-board model for FUNA was presented for clinicians to better understand the various aspects contributing to and implications involved in FUNA. Greater awareness and understanding of the multifactorial nature of FUNA and taking a multifaceted approach are important to effectively reduce this problem.

Keywords: chronic, diabetes mellitus, follow-up, hypertension, systematic review

\section{INTRODUCTION}

Diabetes mellitus (DM) and hypertension, causes of cardiovascular morbidity, are among the leading chronic diseases in the world..$^{(1-3)}$ These two common chronic conditions require regular long-term follow-up as a standard of medical care. ${ }^{(4,5)}$ Delivery of adequate medical care to such patients is impeded by their follow-up non-attendance (FUNA) of outpatient appointments. This may correlate with poor control of their chronic illness, ${ }^{(6,7)}$ higher risk of hospital admissions, ${ }^{(8)}$ decreased clinic efficiency ${ }^{(9)}$ and mortality. ${ }^{(10)}$ It is therefore important to determine the reasons behind poor outpatient clinic attendance in patients with chronic diseases, particularly DM and hypertension.

Many studies in the literature have investigated the effectiveness of different technological interventions, often at the systems level, in reducing the rate of FUNA in patients with chronic conditions, as reported by several recent systematic reviews. ${ }^{(11-13)}$ However, we found that there are a limited number of studies with a comprehensive list of the factors affecting FUNA. For hypertension, our literature search showed that no studies to date provide a complete review of this area. As for DM, after a systematic review done by Griffin et al 18 years ago, there have been no subsequent reviews. ${ }^{(14)}$ Hence, our aim was to provide a systematic literature review of the factors that influence FUNA, the patient characteristics associated with FUNA and the reasons cited for FUNA in patients with these chronic conditions.

\section{METHODS}

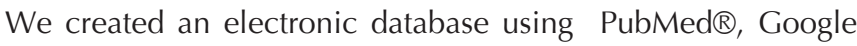
Scholar, PsycINFO ${ }$, Scopus ${ }^{\circledR}$ and Web of Science, based on the PRISMA-P reporting checklist, for our systematic review. Manual searches were carried out using the reference lists of related articles. We reviewed literature from the inception of the databases to December 2016. The keywords used were ((factors OR causes OR reasons) AND (no show OR defaulted OR non-attendance) AND (follow-up OR appointment) AND (hypertension OR diabetes OR hyperlipidaemia OR hyperlipidemia OR metabolic) AND ('outpatient' OR 'general practice' OR 'family practice')). For PubMed, we also searched using MeSH terms: (('diabetes mellitus, type 2' [MeSH] OR 'hypertension' [MeSH]) AND 'lost to follow-up' [MeSH] AND ('outpatient clinics, hospital' [MeSH] OR 'general practice' $[\mathrm{MeSH}])$ ). We included hyperlipidaemia in the search as we had intended to include it; however, as no papers on hyperlipidaemia satisfied our search criteria, we decided to exclude this condition in the remainder of the review.

Two independent reviewers (Samsudin MI and Lee RRS) performed both article inclusion and data extraction. The inclusion criteria of the review were English peer-reviewed journals that studied patient factors and characteristics of nonattendance in Type 2 DM, hypertension and hyperlipidaemia. Studies that only involved patients with Type 1 DM or gestational DM were excluded because the patient demographics were different from those of Type 2 DM. FUNA of education programmes and dietitian consults were excluded. Studies that subsumed FUNA into its multiple outcomes were excluded. Reviews, meta-analyses, case series and case reports, as well as studies that were interventional in nature, were also excluded from the review.

Information on the study design and clinic setting (hospital or community), sample size, country of study, and disease of interest of selected studies was summarised. The quality of the studies was

${ }^{1}$ Duke-NUS Medical School, ${ }^{2}$ Department of Family Medicine and Continuing Care, Singapore General Hospital, Singapore

Correspondence: Dr Rayson Rui Sheng Lee, Alumni, Duke-NUS Medical School, 8 College Road, Singapore 169857. rayson.lee@mohh.com.sg 


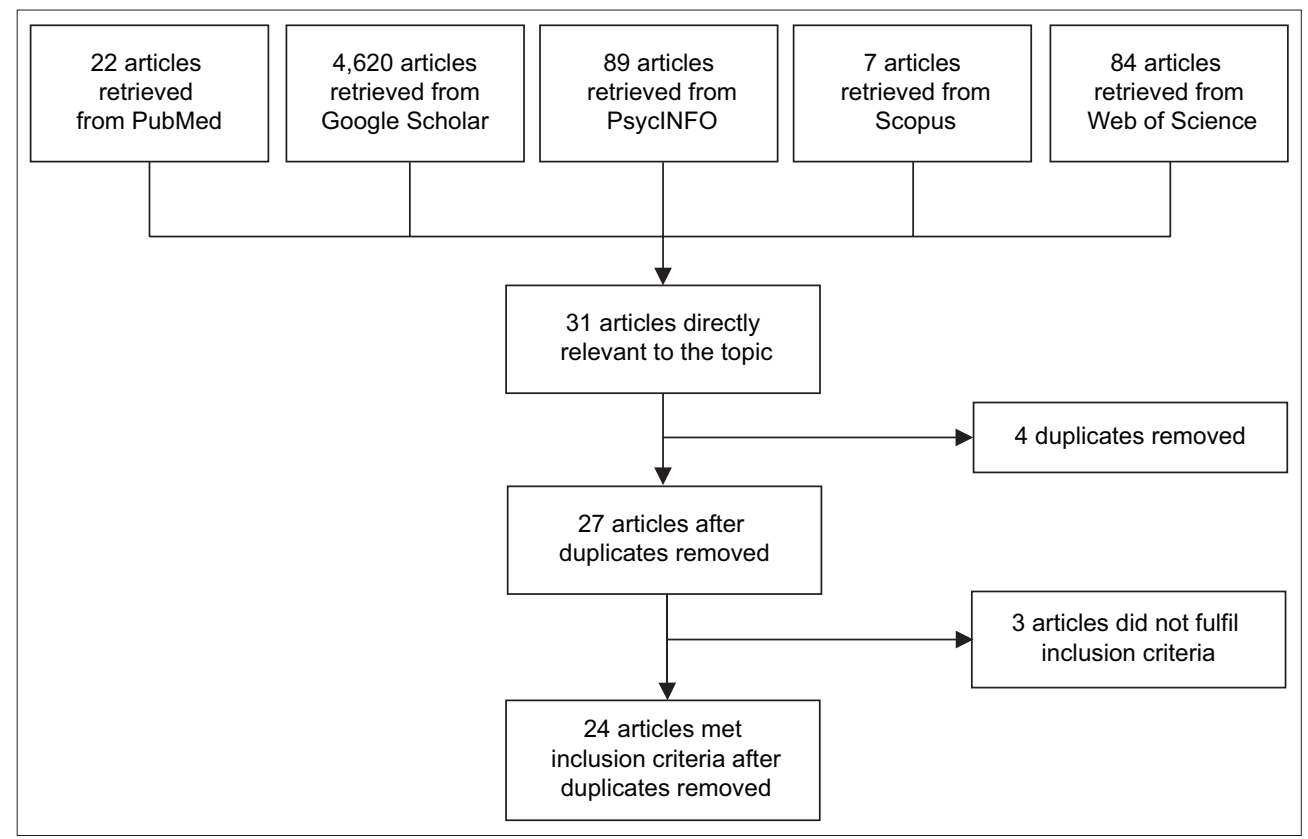

Fig. 1 Flowchart shows the selection of articles for review.

assessed using the modified Newcastle Ottawa Score. ${ }^{(15)}$ Studies were then classified into three main categories and tabulated according to whether each factor showed a positive, negative or neutral association with FUNA. Anecdotal reasons given by patients for their FUNA were also presented. These 'reasons' for FUNA did not have any statistical analysis done as reflected in the original studies and, as such, were distinguished from 'factors' in our review. A target-board model of FUNA in patients with chronic diseases was proposed to better understand the delicate factors that affect FUNA in this group of patients.

\section{RESULTS}

A total of 4,822 articles were retrieved by our searches, comprising 22 PubMed, 4,620 Google Scholar, 89 PyscINFO, seven Scopus and 84 Web of Science articles. Out of 31 articles that were relevant to our objective, four were duplicates, while another three articles did not fulfil the inclusion criteria, leaving 24 articles for review (Fig. 1). Among these 24 articles, 15 (62.5\%) were cohort studies, $6(25.0 \%)$ were cross-sectional studies, and $3(12.5 \%)$ were case-control studies.

The country, sample size and disease of interest for each study are summarised in Table I. A total of 83 factors and 36 reasons were procured for FUNA in diabetic and hypertensive patients. Tables II-IV contain quantitative data detailing the factors and studies that had a positive, neutral or negative association with FUNA. Several studies showed mixed results, which were also indicated in each table, as some studies reported univariate versus multivariate results, while some reported results at two different time points. The 83 factors reviewed were classified into three categories: patient factors; medication and disease factors; and healthcare provider factors. Qualitative data in the form of anecdotal reasons cited by patients for FUNA is shown in Table $\mathrm{V}$.

\section{Patient factors}

A total of 32 patient factors from 19 studies $^{(16-34)}$ were identified (Table II). The studies investigated the different patient factors that may affect an individual's willingness and ability to return for followup at their respective health clinics. The results were summarised under the following categories: mental state, demographics, alcohol and tobacco use, knowledge/beliefs/attitudes, and others. Mental state factors that were associated with FUNA included patients who had interpersonal relations that were dismissing, where they felt the need to be independent and were not comfortable trusting others; and interpersonal relations that were fearful, where patients were afraid of intimacy due to fear of rejection. ${ }^{(21)}$ Depression, on the other hand, was not associated with FUNA. ${ }^{(30,31)}$

While there are several studies that showed a positive association between FUNA and certain demographic factors such as age and gender, many more studies showed that these factors as well as type and status of employment were not associated with FUNA. ${ }^{(16-20,22-26,29-33)}$ Two studies showed varied results regarding a positive association between FUNA and patients with English as their primary language and between FUNA and education status. ${ }^{(18,30)}$ For alcohol, smoking and substance use, several studies showed no association with FUNA. ${ }^{(19,27,29,30,33)}$ However, three studies found that FUNA was positively associated with smoking. ${ }^{(18,19,23)}$ As for knowledge, beliefs and attitudes, patients with FUNA were positively associated with poor knowledge of their disease, belief that their medications do not work and lack of satisfaction with their DM care. ${ }^{(30,31,33)}$ Two studies on patients' recommended therapeutic diet had differing associations of FUNA. ${ }^{(25,33)}$

Other patient factors associated with FUNA included: having missed appointments in the past; having a community services card that allowed for larger health service subsidies; a longer time since the previous medical appointment; having had a hospital admission since their previous appointment; and not having insurance to cover their medical bills. ${ }^{(18,26,30,32}$ 
Table I. List of studies included in this systematic review.

\begin{tabular}{|c|c|c|c|c|}
\hline Author, yr, country & Study design, setting & $\mathbf{n}$ & Disease & NOS* \\
\hline Archibald and Gill, 1992, UK ${ }^{(16)}$ & Case-control, community & 37 & Type 2 DM & $4,1,1$ \\
\hline Babwah et al, 2006, Trinidad and Tobago ${ }^{(17)}$ & Cross-sectional, hospital & 360 & Type 2 DM & $4,2,1$ \\
\hline Benoit et al, 2004, USA ${ }^{(18)}$ & Case-control, community and hospital & 573 & Type 2 DM & $4,2,2$ \\
\hline Busnello et al, 2001, Brazil(19) & Cohort, hospital & 945 & Hypertension & $4,2,3$ \\
\hline Chew et al, 2009, Malaysia(20) & Cohort, hospital & 57,780 & Type 2 DM & $4,2,3$ \\
\hline Gill and Owens, 1998, UK(22) & Cohort, hospital & 7,015 & Both Type 1 and 2 DM & $3,1,2$ \\
\hline Graber et al, 1992, USA ${ }^{(23)}$ & Cohort, community & 422 & Both Type 1 and 2 DM & $4,1,3$ \\
\hline Wilkinson and Daly, 2012, New Zealand ${ }^{(35)}$ & Cohort, community & 142 & Both Type 1 and 2 DM & $3,1,3$ \\
\hline Hammersley et al, 1985, UK ${ }^{(24)}$ & Cohort, hospital & 162 & Both Type 1 and 2 DM & $4,1,3$ \\
\hline Kawahara et al, 1994, Japan (25) & Cohort, community & 109 & Type 2 DM & $4,1,3$ \\
\hline Lloyd et al, 1990, UK(37) & Cohort, hospital & 715 & Both Type 1 and 2 DM & $3,1,2$ \\
\hline Low et al, 2016, Singapore ${ }^{(26)}$ & Cohort, hospital & 1,645 & Both Type 1 and 2 DM & $4,2,3$ \\
\hline Malcolm et al, 2013, Canada ${ }^{(27)}$ & Cohort, community & 193 & Type 2 DM & $4,2,3$ \\
\hline Masding et al, 2010, UK ${ }^{(28)}$ & Cohort, hospital & 114 & Both Type 1 and 2 DM & $4,2,2$ \\
\hline Masuda et al, 2006, Japan ${ }^{(29)}$ & Cohort, community & 160 & Type 2 DM & $4,2,2$ \\
\hline Ngwenya et al, 2009 , South Africa ${ }^{(38)}$ & Cohort, hospital & 76 & Both Type 1 and 2 DM & $4,2,1$ \\
\hline Nwabuo et al, 2014, USA ${ }^{(30)}$ & Cross-sectional, hospital & 185 & Hypertension & $4,2,2$ \\
\hline Parker et al, 2012, USA ${ }^{(31)}$ & Cohort, community & 12,957 & Type 2 DM & $4,2,2$ \\
\hline Simmons and Clover, 2007, New Zealand ${ }^{(32)}$ & Case-control, community & 89 & Type 2 DM & $4,2,3$ \\
\hline Simmons and Fleming, 2000, New Zealand ${ }^{(33)}$ & Cross-sectional, community & 1,488 & Both Type 1 and Type 2 DM & $3,2,3$ \\
\hline Thongsai, 2015, Thailand ${ }^{(34)}$ & Cross-sectional, hospital & 442 & Type 2 DM & $3,1,2$ \\
\hline
\end{tabular}

*The three values in each study correspond to the selection (out of 4), comparability (out of 2) and outcome (out of 3 ) sections of the NOS, respectively. DM: diabetes mellitus; NOS: Newcastle Ottawa Score

\section{Disease and medication factors}

35 disease and medication factors from 15 studies $^{(16,18-20,22-25,27-33}$ were elucidated (Table III). While several studies revealed that poor disease control, especially baseline glycated haemoglobin (HbA1c) level, was positively associated with FUNA, a number of other studies showed that higher systolic and diastolic blood pressure, poor lipid profile, and baseline $\mathrm{HbA} 1 \mathrm{c}$ had no association with FUNA. ${ }^{16,18,20,24,25,27-31)}$ Several studies showed that high body mass index and a longer duration of DM did not have any association with FUNA. ${ }^{(16,18,23,24,32)}$ As for the presence of complications of disease in patients, some studies showed that diabetic retinopathy and nephropathy had no association with FUNA, while several others showed a positive or varied association. ${ }^{(16,19,20,24,27,29,30,32,33)}$

Mixed conclusions were drawn regarding insulin treatment, a medication factor, as evidenced by several studies showing positive, negative and no association with FUNA. . $18,20,23,27,32,33$ While some studies found a positive association between FUNA and the type of medication that patients were taking, ${ }^{(23,29,33)}$ others found no association. ${ }^{(18,20,24)}$ Another study showed varied results. ${ }^{(27)}$ One study showed that other medication factors associated with FUNA included non-adherence to medication, difficulty paying for medication, having experienced side effects of medications and high medication charges upon hospital discharge. ${ }^{(30)}$

\section{Healthcare provider factors}

16 factors related to healthcare providers from eight studies $^{(20,23,26,27,29,31-33)}$ were identified and categorised into scheduling factors, provider characteristics, and factors that influence the doctor-patient relationship (Table IV).

In terms of scheduling, duration between appointments and scheduled month of the year, particularly between January and July, were associated with FUNA. ${ }^{26,27)}$ For healthcare provider characteristics, more studies ${ }^{(27,29,32)}$ showed that distance from the clinic was not associated with FUNA. Other provider characteristic factors that had a positive association with FUNA included not having a dedicated primary physician and a higher number of re-referrals from an intra-hospital source. ${ }^{(26,27,31)}$ Interestingly, out-of-pocket expense and the type of setting (urban or rural) did not show any association with FUNA. ${ }^{27,32)}$ Under factors that influence the doctor-patient relationship, FUNA was positively associated with patients who were dissatisfied with their care and lacked trust in their providers. ${ }^{(31,33)}$

\section{Reasons cited by patients}

In addition to the quantitative factors elucidated above, a total of 36 reasons were qualitatively reported from ten studies (Table V). ${ }^{(16,24,25,30,32,35-39)}$ Commonly cited reasons related to the patient included: work commitments; having a busy schedule or 
Table II. Relationship between patient factors and follow-up non-attendance in the studies reviewed.

\begin{tabular}{|c|c|c|c|}
\hline \multirow[t]{2}{*}{ Factor } & \multicolumn{3}{|c|}{ Study no. } \\
\hline & Positive & Neutral & Negative \\
\hline \multicolumn{4}{|l|}{ Mental state } \\
\hline Attachment style & 21 & & \\
\hline Depression & & 30,31 & \\
\hline \multicolumn{4}{|l|}{ Demographics } \\
\hline Younger age & $22,26,29,31,33$ & $16,18,19,20,23,24,25,27,30,32$ & 28 \\
\hline Age at diagnosis & 33 & 32 & 31 \\
\hline Male gender & $17,20,26$ & $16,18,19,23,24,25,27,28,30,31,32,33$ & \\
\hline Ethnicity & $18,26,31,33$ & $20^{*}, 32$ & \\
\hline Married & & 30,32 & \\
\hline Employed & 33 & $29,30,31,32$ & \\
\hline Type of employment & 31 & & \\
\hline Household income & & 31,32 & \\
\hline Language & $18^{*}$ & & \\
\hline No. in household & & 32 & \\
\hline Type of occupation & & 29,33 & \\
\hline Education status & $19,30 *, 31$ & 33 & 32 \\
\hline Age at completing school & & 33 & \\
\hline Partner with DM & & & 32 \\
\hline Time at address & & 33 & \\
\hline \multicolumn{4}{|l|}{ Alcohol and tobacco use } \\
\hline Alcohol consumption & & $19,29,30$ & \\
\hline Smoking & $18,19,23$ & $27,29,33$ & \\
\hline Substance use & & 30 & \\
\hline \multicolumn{4}{|l|}{ Knowledge/beliefs/attitudes } \\
\hline Belief that medications do not work & 30 & & \\
\hline Poor knowledge of DM or hypertension & $30,31,33$ & & \\
\hline Perceived knowledge deficit & & 32 & \\
\hline Illness perception & & 34 & \\
\hline DM interferes with life & & 31,32 & \\
\hline Not satisfied with DM care & 33 & & \\
\hline Psychological barrier & & 31,32 & \\
\hline Lifestyle (diet or exercise) & & 25 & 25,33 \\
\hline \multicolumn{4}{|l|}{ Others } \\
\hline Previously missed appointments & 26 & & \\
\hline Accessibility (financial) & $30,31,32$ & 18 & 18 \\
\hline Time since previous attendance & 32 & & \\
\hline Hospitalisation since previous appointment & 26 & & \\
\hline
\end{tabular}

*Varied results (not all in one category). DM: diabetes mellitus

having alternative appointments; the perception that their DM was not dangerous or that they were not ill enough; the inability to afford clinic or medication expenses; having forgotten their appointment; or transport difficulties. ${ }^{(16,24,25,30,32,35-39)}$ As for reasons related to healthcare providers, transport logistics such as cost and lack of accessibility, as well as patients perceiving the clinic sessions to be useful, were cited in most of the studies. ${ }^{(16,25,30,32,35-38)}$

\section{Target-board model of FUNA in patients with chronic disease}

The various factors elucidated in this study can be broadly categorised into patient, disease and healthcare factors. Based on this, we proposed the target-board model of FUNA in patients with chronic disease to allow healthcare providers to understand these factors better and to apply this improved understanding to address FUNA in their institutions or clinics (Fig. 2).

\section{DISCUSSION}

This systematic review involved a comprehensive literature review of the factors affecting FUNA in patients with hypertension and Type 2 DM. To the best of our knowledge, the last similar study was done more than 18 years ago. ${ }^{(14)}$ The present review gives an overview of the types and numbers of studies that showed various associations with the factors investigated. 
Table III. Relationship between disease/medication factors and follow-up non-attendance in the studies reviewed.

\begin{tabular}{|c|c|c|c|}
\hline \multirow[t]{2}{*}{ Factor } & \multicolumn{3}{|c|}{ Study no. } \\
\hline & Positive & Neutral & Negative \\
\hline \multicolumn{4}{|l|}{ Disease factor } \\
\hline High diastolic BP & $18,24,30$ & $20^{*}, 27$ & \\
\hline High systolic BP & 18,31 & $20,24,27,30$ & \\
\hline High baseline BP & 18,25 & 19,32 & \\
\hline High baseline glucose (plasma) & & 24,25 & 29 \\
\hline High baseline $\mathrm{HbA} 1 \mathrm{c}$ & $16,18^{*}, 20,24,27,28,31$ & $23,25,32$ & 27,29 \\
\hline High baseline insulin & 25 & & \\
\hline High total cholesterol & & $25,27,32$ & \\
\hline High baseline LDL & 20,31 & 25,27 & \\
\hline High baseline triglyceride & 25 & 27,32 & \\
\hline High baseline HDL & & 27,32 & 25 \\
\hline Total cholesterol to HDL ratio & 25 & 27 & \\
\hline Urine albumin-to-creatinine ratio/absolute creatinine & & 32 & \\
\hline High BMI/obesity & $24,25^{*}$ & $16,18,20,23,27,32$ & \\
\hline Attaining treatment targets & & 20 & \\
\hline DM Type 2 compared to Type 1 & & $23,27,28$ & \\
\hline Duration of DM (longer) & $27^{*}$ & $16,18,20 *, 23,24,32$ & 31,33 \\
\hline Duration of hypertension/dyslipidaemia & & $20^{*}$ & 19 \\
\hline Poor skin/nail/foot care & 32 & & \\
\hline Family history (first-degree relative) & & 19,25 & \\
\hline Previous DM diagnosis/gestational DM & 29,33 & & \\
\hline Diagnosed with symptoms/during screening & $33^{*}$ & & \\
\hline Comorbidities present & $20^{*}, 33$ & 27,30 & \\
\hline Complications present & $16,20,24^{*}, 27^{*}, 32^{*}, 33^{*}$ & $19,29,30$ & 22 \\
\hline Mortality risk category & 31 & 30 & \\
\hline Emergency room visits & 27 & & \\
\hline \multicolumn{4}{|l|}{ Medication factor } \\
\hline Currently taking BP medication & 33 & 20 & 32 \\
\hline Not prescribed medication & 23,32 & 18 & \\
\hline On insulin treatment & 27,33 & 18 & $20,23,32$ \\
\hline On aspirin/antiplatelet & & 27 & 20 \\
\hline Treatment regime (medication) & $23,27^{*}, 29,33$ & $18,20,24$ & \\
\hline Non-adherence to medication & 30 & & \\
\hline No medication coverage & 30 & & \\
\hline Medication coverage with copayment & & 30 & \\
\hline Experienced side effects & 30 & & \\
\hline High cost of discharge medication & 30 & & \\
\hline
\end{tabular}

*Varied results (not all in one category). BMI: body mass index; BP: blood pressure; DM: diabetes mellitus; HbA1c: glycated haemoglobin; HDL: high-density lipoprotein; LDL: low-density lipoprotein

Three categories of factors are presented in this target-board model of FUNA (Fig. 2). Each arrow in the model represents a domain of factors that healthcare providers, especially clinicians, should be aware of when dealing with the issue of FUNA. In order to achieve the desired goals represented by the target board in this model, all three domains have to be addressed adequately and collectively in order to effectively improve patient compliance, follow-up attendance and, ultimately, patient therapeutic outcomes. We hope that this model can achieve similar effects as the Wong-Baker FACES
Pain Rating Scale and facilitate interaction between the patient and clinician. ${ }^{(40)}$

The prevalence of non-attendance at diabetic clinics varies significantly worldwide, ranging from as low as $4 \%-8 \%$ to as high as $64 \%$ in the United Kingdom alone; ${ }^{(7,8,14)}$ a study done in Singapore published recently cited a prevalence that is in between those numbers. ${ }^{(26)}$ Awareness and understanding of these patient characteristics will help clinicians to identify patients who are at high risk of defaulting based on factors such as smoking and ethnicity, as well as baseline $\mathrm{HbA} 1 \mathrm{c}$ and low-density lipoprotein 
Table IV. Relationship between healthcare provider factors and follow-up non-attendance in the studies reviewed.

\begin{tabular}{|c|c|c|c|}
\hline \multirow[t]{2}{*}{ Factor } & \multicolumn{3}{|c|}{ Study no. } \\
\hline & Positive & Neutral & Negative \\
\hline \multicolumn{4}{|l|}{ Schedule } \\
\hline No. of scheduled appointments & 26 & & 27 \\
\hline Consultation type & & 26 & \\
\hline Scheduled time/day of the week & & 26 & \\
\hline Scheduled month of the year & 26 & & \\
\hline First appointment & & & 26 \\
\hline Duration between appointments & 26,27 & & \\
\hline \multicolumn{4}{|l|}{ Provider characteristics } \\
\hline Type of clinic & 20 & & \\
\hline Distance from clinic/travel issues & 23 & $27,29,32$ & \\
\hline Higher no. of re-referrals & 27 & & \\
\hline Referral source (intra-hospital) & 26 & & \\
\hline Out of pocket expense & & 32 & \\
\hline Urban vs. rural setting & & 27 & \\
\hline Percentage of visits where medication changed & 27 & & \\
\hline No designated primary care provider & 31 & & \\
\hline \multicolumn{4}{|l|}{ Doctor-patient relationship } \\
\hline Dissatisfied with care & 33 & & \\
\hline Lack of trust in provider & 31 & & \\
\hline
\end{tabular}

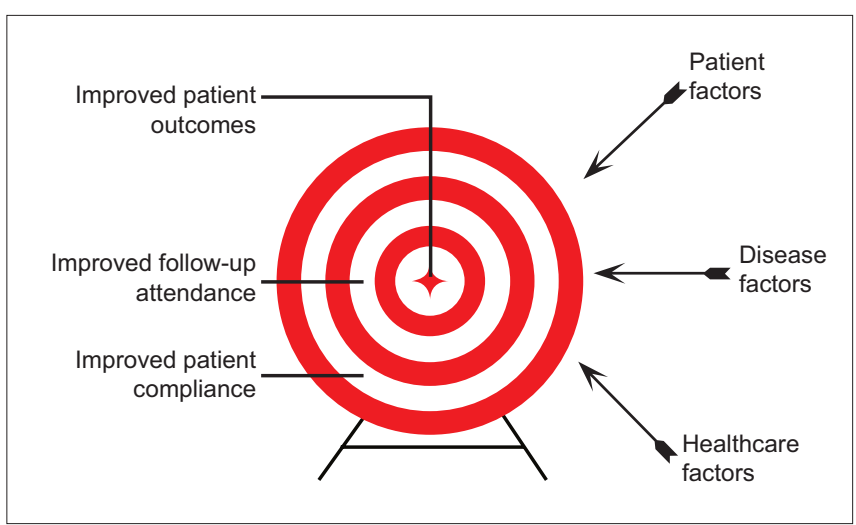

Fig. 2 Target board diagram shows the approach to follow-up nonattendance.

levels, thereby allowing for closer attention and care. It is important, however, to understand the regional context of the study when considering its clinical relevance.

A good doctor-patient relationship was shown to be associated with better patient attendance at chronic disease clinics, which is in line with our review findings. ${ }^{(41,42)}$ Moving away from a paternalistic doctor-patient relationship to one that emphasises patient empowerment helps patients to make informed and early decisions about their plans of care, thus improving diabetic patient care. ${ }^{(43)}$ Healthcare providers can employ these methods in their practice to reduce patients' lack of trust and dissatisfaction, thus improving FUNA and ultimately patient outcomes.

Other factors affecting non-attendance can be improved through interventions in the healthcare system. For example, for the problem of long clinic waiting times, the simple introduction of efficient registration systems was shown to reduce the number of patients lost to follow-up in a general practice diabetic care clinic. ${ }^{(44)}$ Additionally, educating the patients about how the clinic functions through an orientation video, instead of pamphlets, improved non-attendance in outpatient clinics. ${ }^{(45)}$ This improvement was even more remarkable when videos were also used to emphasise the importance of keeping appointments and explain the consequences of continual FUNA. . $^{(46)}$

A study done in Singapore by Low et al showed that several factors were positively associated with FUNA in diabetic patients, including ethnicity and longer intervals between appointments. ${ }^{(26)}$ This was in agreement with several other studies in our review. However, as opposed to the Singapore study, a greater number of studies showed no association between FUNA and the age of the patients, and one study showed that having fewer appointments was associated with FUNA. In addition, no other studies looked at a previous history of FUNA and the month of scheduled appointment in the year as factors affecting FUNA.

Comparing our study to that done 18 years ago by Griffin et al, ${ }^{(14)}$ we found that some characteristics were similarly associated with FUNA, such as smoking, poorer education and employment status, previous missed appointments, and little patient knowledge about their disease. Age and psychological issues, however, had no significant association with FUNA. With regard to disease, both articles identified that patients who exhibited FUNA had more comorbidities and complications of disease, and had higher mortality risk status. FUNA was also associated with patients who were not prescribed medication, suggesting that patients with good diabetic control were also more likely to default. Unlike Griffin et al, our study found less association with obesity. For provider factors, we similarly found that dissatisfaction with care and long interval between appointments were positively associated with FUNA. Conversely, more papers showed that transport issues 
Table V. Reasons given for follow-up non-attendance (qualitative findings from studies).

\begin{tabular}{|c|c|}
\hline Factor & Study no. \\
\hline \multicolumn{2}{|l|}{ Patient } \\
\hline Arrived late at the clinic and found it closed & 38 \\
\hline At work/school and could not take leave to attend clinic & $16,35,38$ \\
\hline Away/out of town at the time & 37,38 \\
\hline Appointment during the holiday period & 39 \\
\hline Busy schedule/opportunity cost/other personal appointments & $25,36,38,39$ \\
\hline Claimed DM is gone/not ill enough/risk perception & $24,32,36,39$ \\
\hline Confused about appointment time & 35 \\
\hline Could not read appointment card due to bad eyesight & 38 \\
\hline Could not walk due to illness & 38 \\
\hline Could not afford to attend the clinic/could not afford medicine & $36,38,32$ \\
\hline Dead & 37 \\
\hline Denies non-attendance & 38 \\
\hline Dislikes attending hospital & 25 \\
\hline Fear of side effects of medication & 39 \\
\hline Forgot & $30,35,37,38$ \\
\hline Got dates mixed up & 37,38 \\
\hline Ill at the time & 35,37 \\
\hline Lost appointment card & $37,38,39$ \\
\hline Pregnant & 37 \\
\hline Already seeing a DM specialist nurse & 37 \\
\hline Traditional vs. Western medical care (prefer traditional)/pursuing alternative treatment & 36,39 \\
\hline Unaware of appointment & 35 \\
\hline Would have lost time off work & 24,37 \\
\hline \multicolumn{2}{|l|}{ Healthcare provider } \\
\hline Attended alternative clinic for DM/transferring clinic & 25,37 \\
\hline Clinic not helpful & $30,35,37$ \\
\hline Communication barriers/inadequate explanations & 16,36 \\
\hline Clinic too crowded & 16 \\
\hline Fear of being reprimanded by $\mathrm{CHW/unfriendly} \mathrm{staff}$ & 32,36 \\
\hline Different doctor each visit/not seeing consultant & 16 \\
\hline Hospital inpatient at the time & 37,38 \\
\hline Lack of trust in $\mathrm{CHW}$ & 36 \\
\hline Lack of acceptance of CHW referral (not qualified) & 36 \\
\hline No appointment received & 37 \\
\hline No transport/transport cost/clinic too far & $16,25,30,32,35,36,37,38$ \\
\hline Waiting time too long & 16,24 \\
\hline \multicolumn{2}{|l|}{ Others } \\
\hline Weather was bad & 38 \\
\hline
\end{tabular}

CHW: community health worker; DM: diabetes mellitus

and distance from the clinic were not significantly associated with FUNA ${ }^{(27,29,32)}$ compared with one earlier paper by Graber et al showing a positive association. ${ }^{(23)}$ Other factors found to be significantly associated with FUNA in Griffin et al's paper, such as long waiting times and poor communication between the healthcare professional and patient, were some of the reasons cited in Table V.

This review was limited by the search terms and databases used in our search strategy. We excluded interventional studies because we believed that they would have been tested based on findings from previous studies that were likely to be included in our review. Studies from specialist nurse clinics were also excluded, as the setting does not fall within the intended scope of our review.

Despite the personal, clinical and systemic factors that were extracted, a weakness of the present study is that the conflicting nature of research findings in this area prevented substantial conclusions from being made. Examples of conflicting findings in different primary studies include, but are not limited to, age, gender, type of medication, presence of comorbidities 
and complications that had any association with FUNA. Other reviews performed on clinic non-attendance have shown similar results and cited differing definitions of non-attendance, research methodologies and populations studied as potential reasons for such discordances. ${ }^{(47,48)}$ In addition, we acknowledge that the qualitative reasons for FUNA in this paper were not exhaustive. They were sourced as a secondary finding among papers that were otherwise selected for their quantitative content. However, there is significant value in synthesising a systematic review of the qualitative reasons in the literature, as it may offer more actionable insights to the FUNA problem.

In conclusion, 83 factors were found to be associated with FUNA in hypertensive and diabetic patients. Greater focus should be given by healthcare providers on the multifactorial nature of FUNA, which includes patient, disease and healthcare provider factors, in order to effectively manage it and maximise therapeutic outcomes in these patients.

\section{REFERENCES}

1. Yach D, Hawkes C, Gould CL, Hofman KJ. The global burden of chronic diseases: overcoming impediments to prevention and control. JAMA 2004; 291:2616-22.

2. Roger VL, Go AS, Lloyd-Jones DM, et al; American Heart Association Statistics Committee and Stroke Statistics Subcommittee. Heart disease and stroke statistics--2011 update: a report from the American Heart Association. Circulation 2011; 123:e18-e209.

3. Wagner EH, Austin BT, Davis C, et al. Improving chronic illness care: translating evidence into action. Health Aff (Millwood) 2001; 20:64-78.

4. James PA, Oparil S, Carter BL, et al. 2014 evidence-based guideline for the management of high blood pressure in adults: report from the panel members appointed to the Eighth Joint National Committee (JNC 8). JAMA 2014; 311:507-20.

5. Inzucchi SE, Bergenstal RM, Buse JB, et al. Management of hyperglycemia in type 2 diabetes, 2015: a patient-centered approach: update to a position statement of the American Diabetes Association and the European Association for the Study of Diabetes. Diabetes Care 2015; 38:140-9.

6. Park WB, Choe PG, Kim SH, et al. One-year adherence to clinic visits after highly active antiretroviral therapy: a predictor of clinical progress in HIV patients. J Intern Med 2007; 261:268-75.

7. Karter AJ, Parker MM, Moffet HH, et al. Missed appointments and poor glycemic control: an opportunity to identify high-risk diabetic patients. Med Care 2004; 42:110-5.

8. Nuti LA, Lawley M, Turkcan A, et al. No-shows to primary care appointments: subsequent acute care utilization among diabetic patients. BMC Health Serv Res 2012; 12:304.

9. Capko J. The price you pay for missed appointments. J Med Pract Manage 2007; 22:368.

10. Bailey JE, Wan JY, Tang J, Ghani MA, Cushman WC. Antihypertensive medication adherence, ambulatory visits, and risk of stroke and death. J Gen Intern Med 2010; 25:495-503.

11. Guy R, Hocking J, Wand $\mathrm{H}$, et al. How effective are short message service reminders at increasing clinic attendance? A meta-analysis and systematic review. Health Serv Res 2012; 47:614-32.

12. Hasvold PE, Wootton R. Use of telephone and SMS reminders to improve attendance at hospital appointments: a systematic review. J Telemed Telecare 2011; 17:358-64.

13. Lin $\mathrm{H}, \mathrm{Wu} X$. Intervention strategies for improving patient adherence to follow-up in the era of mobile information technology: a systematic review and metaanalysis. PLoS One 2014; 9:e104266.

14. Griffin SJ. Lost to follow-up: the problem of defaulters from diabetes clinics. Diabet Med 1998; 15 Suppl 3:S14-24.

15. Wells G, Shea BJ, O'Connell D, Petersen JE, Welch V. The Newcastle-Ottawa Scale (NOS) for assessing the quality of case-control studies in meta-analyses. Eur J Epidemiol 2011; 25:603-5.

16. Archibald LK, Gill GV. Diabetic clinic defaulters--who are they and why do they default? Pract Diabetes Int 1992; 9:13-4.

17. Babwah F, Baksh S, Blake L, et al. The role of gender in compliance and attendance at an outpatient clinic for type 2 diabetes mellitus in Trinidad. Rev Panam Salud Publica 2006; 19:79-84.
18. Benoit SR, Ji M, Fleming R, Philis-Tsimikas A. Predictors of dropouts from a San Diego diabetes program: a case control study. Prev Chronic Dis 2004; 1:A10.

19. Busnello RG, Melchior R, Faccin C, et al. Characteristics associated with the dropout of hypertensive patients followed up in an outpatient referral clinic. Arq Bras Cardiol 2001; 76:349-54.

20. Chew BH, Lee PY, Shariff-Ghazali S, et al. Predictive factors of follow-up nonattendance and mortality among adults with type 2 diabetes mellitus- an analysis of the Malaysian diabetes registry 2009. Curr Diabetes Rev 2015; 11:122-31.

21. Ciechanowski P, Russo J, Katon W, et al. Where is the patient? The association of psychosocial factors and missed primary care appointments in patients with diabetes. Gen Hosp Psychiatry 2006; 28:9-17.

22. Gill G, Owens L. Attendance failures in diabetes clinics. Pract Diabetes Int $1998 ; 15: 141-2$.

23. Graber AL, Davidson P, Brown AW, McRae JR, Woolridge K. Dropout and relapse during diabetes care. Diabetes Care 1992; 15:1477-83.

24. Hammersley MS, Holland MR, Walford S, Thorn PA. What happens to defaulters from a diabetic clinic? Br Med J (Clin Res Ed) 1985; 291:1330-2.

25. Kawahara R, Amemiya T, Yoshino M, et al. Dropout of young non-insulindependent diabetics from diabetic care. Diabetes Res Clin Pract 1994; 24:181-5.

26. Low SK, Khoo JK, Tavintharan S, Lim SC, Sum CF. Missed appointments at a diabetes centre: not a small problem. Ann Acad Med Singapore 2016; 45:1-5.

27. Malcolm JC, Maranger J, Taljaard M, et al. Into the abyss: diabetes process of care indicators and outcomes of defaulters from a Canadian tertiary care multidisciplinary diabetes clinic. BMC Health Serv Res 2013; 13:303.

28. Masding MG, Klejdys S, MacHugh B, et al. Non-attendance at a diabetes transitional clinic and glycaemic control. Pract Diabetes Int 2010; 27:109-110i.

29. Masuda Y, Kubo A, Kokaze A, et al. Personal features and dropout from diabetic care. Environ Health Prev Med 2006; 11:115-9.

30. Nwabuo CC, Dy SM, Weeks K, Young JH. Factors associated with appointment non-adherence among African-Americans with severe, poorly controlled hypertension. PLoS One 2014; 9:e103090.

31. Parker MM, Moffet HH, Schillinger D, et al. Ethnic differences in appointmentkeeping and implications for the patient-centered medical home--findings from the Diabetes Study of Northern California (DISTANCE). Health Serv Res 2012; 47:572-93.

32. Simmons D, Clover G. A case control study of diabetic patients who default from primary care in urban New Zealand. Diabetes Metab 2007; 33:109-13.

33. Simmons D, Fleming C. Prevalence and characteristics of diabetic patients with no ongoing care in South Auckland. Diabetes Care 2000; 23:1791-3.

34. Thongsai S. Do illness perceptions predict the attendance rate at diabetic outpatient clinic? Glob J Health Sci 2014; 7:254-62.

35. Wilkinson J, Daly M. Reasons for non-attendance: audit findings from a nurseled clinic. J Prim Health Care 2012; 4:39-44.

36. Levitt NS, Puoane T, Denman CA, et al. Referral outcomes of individuals identified at high risk of cardiovascular disease by community health workers in Bangladesh, Guatemala, Mexico, and South Africa. Glob Health Action 2015; $8: 26318$.

37. Lloyd J, Sherriff R, Fisher M, Burns-Cox C. Non-attendance at the diabetic clinic. Pract Diabetes Int 1990; 7:228-9.

38. Ngwenya BT, van Zyl DG, Webb EM. Factors influencing non-attendance of clinic appointments in diabetic patients at a Gauteng hospital in 2007/2008. J Endocrinol Metab Diabetes S Afr 2009; 14:106.

39. Wiwanitkit V. Loss of follow-up of diabetic patients: what are the reasons? Indian J Endocrinol Metab 2011; 15:144.

40. Shavit I, Kofman M, Leder M, Hod T, Kozer E. Observational pain assessment versus self-report in paediatric triage. Emerg Med J 2008; 25:552-5.

41. Glogow E. Effects of health education methods on appointment breaking. Public Health Rep 1970; 85:441-50.

42. Roter DL. Patient participation in the patient-provider interaction: the effects of patient question asking on the quality of interaction, satisfaction and compliance. Health Educ Monogr 1977; 5:281-315.

43. Feste C. A practical look at patient empowerment. Diabetes Care 1992; 15:922-5.

44. Griffin S, Kinmonth AL. Diabetes care: the effectiveness of systems for routine surveillance for people with diabetes. Cochrane Database Syst Rev 2000; (2):CD000541.

45. Barry SP, Daniels AA. Effecting change in outpatient failed appointments. J Fam Pract 1984; 18:739-42.

46. Kish JP, Yaekle S, French L. Improvement of appointment keeping behaviour using a one minute video. North Am Prim Care Res Group Annu Sci Meet 1997.

47. Bean AG, Talaga J. Appointment breaking: causes and solutions. J Health Care Mark 1992; 12:14-25.

48. Gucciardi E. A systematic review of attrition from diabetes education services: strategies to improve attrition and retention research. Can J Diabetes 2008; 32:53-65. 